\title{
Genotypic characterisation of endemic VanA Enterococcus faecium strains isolated in a paediatric hospital
}

\author{
G. BARNAUD and E. BINGEN
}

Service de Microbiologie, Hôpital Robert Debré, 75019 Paris and Laboratoire d'Etudes de Génétique Bacteriénne dans les infections de l'Enfant (EA3105), Université Denis Diderot, Paris 7, France

\begin{abstract}
A total of 36 vancomycin-resistant Enterococcus faecium isolates obtained from 30 patients during a 28-month period in a paediatric university hospital was analysed by pulsed-field gel electrophoresis (PFGE) combined with Southern hybridisation of a vanAspecific DNA probe. All the isolates hybridised with the vanA probe. Seventeen different PFGE patterns and 11 PFGE subtypes were identified among the 36 clinical isolates, and the size of probe-positive bands ranged from c. 30 to $300 \mathrm{~kb}$. These data are consistent with an increase in the overall genomic diversity of vancomycin-resistant $E$. faecium isolates during the study period. Two periods were distinguished. The prevalence of a single clone in the initial period suggested transmission between patients in three wards. During the following period, multiple genotypes of vancomycinresistant $E$. faecium were identified, indicative of multiple introductions or the dissemination of resistance genes by recombinant transposition.
\end{abstract}

\section{Introduction}

Nosocomial enterococcal infection is frequent in adults and is mainly caused by strains with multiple resistance to antibiotics [1-3]. The first reports of vancomycin resistance among enterococci were published in the late 1980 s in the UK and France [4,5]. Subsequently, vancomycin-resistant enterococci (VRE) have been reported widely as a cause of nosocomial infections in the USA [6-9] and Europe [10-12]. VRE have also been identified as a cause of paediatric nosocomial infections [13-19]. Knowledge of the epidemiology of VRE infection is essential for the control of further spread. During routine stool investigations of immunocompromised patients (performed twice weekly in this hospital), 36 VRE isolates were obtained from 30 patients in four wards over a 28-month period. Molecular fingerprinting techniques were used to gain insight into the patterns of epidemic spread of VRE in this paediatric hospital.

Received 25 May 1999; revised version accepted 27 Jan. 2000.

Corresponding author: Professor E. Bingen (e-mail: edouard.bingen@rdb.ap-hop-paris.fr).

\section{Materials and methods}

Study population

Robert Debré Hospital is a 503-bed paediatric university hospital-affiliated tertiary care institution. The hospital has c. 32000 admissions, $>260000$ outpatient visits and $>65000$ emergency department visits annually. Care is provided to substantial numbers of immunosuppressed patients, including those with haematological malignancies, solid tumours, bone marrow and renal transplantation and trauma.

The gastrointestinal tract is the major source of systemic infection in neonates and immunocompromised children. Thus, quantitative and differential stool testing of these patients is done twice weekly in this hospital [20]. The aim is to detect bacterial overgrowth and to identify organisms that may potentially translocate and cause systemic infections [21].

\section{Microbiological methods}

A total of 36 clinical isolates of VRE (RD1-RD36) collected during the study period (July 1994-July 1995) and Jan. 1996-Feb. 1997) was investigated. Thirty-four isolates were from the stools of 29 patients, and two were from blood culture of two patients. For comparison, five epidemiologically unrelated VRE isolates $(\mathrm{a}-\mathrm{e})$ from five adult patients from three 
hospitals in Paris were studied, together with the reference vancomycin-resistant strain E. faecium BM4147 (VanA phenotype), kindly provided by R. Leclercq (Caen, France).

Isolates were identified as enterococci by colony morphology, absence of catalase, Gram's staining, Lancefield group D antigen positivity and conventional biochemical characteristics [22], including aesculin hydrolysis, inability to produce gas from glucose, tolerance of bile and growth in $\mathrm{NaCl} 6.5 \%$. Identity was confirmed by the API 20 STREP system (bioMérieux, Marcy l'Etoile, France).

\section{In-vitro susceptibility to antibiotics}

Susceptibility to antimicrobial agents was determined by means of the disk diffusion method on MuellerHinton Agar (bioMérieux) with incubation at $37^{\circ} \mathrm{C}$. Disks containing gentamicin $500 \mu \mathrm{g}$ and kanamycin $1000 \mu \mathrm{g}$ were used to screen enterococci for high-level resistance to aminoglycosides. The MICs of vancomycin, teicoplanin and amoxicillin were determined by the E-test according to the manufacturer's instructions (AB Biodisk, Dalvagen, Sweden). All isolates were screened for $\beta$-lactamase production by the cefinase disk method (bioMérieux).

\section{Pulsed-field gel electrophoresis (PFGE)}

Enterococci were grown overnight in Brain-Heart Infusion Broth (Sanofi Diagnostics Pasteur, Marne-laCoquette, France), harvested and resuspended in $100 \mu \mathrm{l}$ of cell-suspension buffer (BioRad Laboratories, Richmond, CA, USA). Four $\mu \mathrm{l}$ of lysozyme solution (25 mg/ml; BioRad Laboratories) were added to the suspension and mixed gently; $100 \mu \mathrm{l}$ of low-melting point agarose (BioRad Laboratories) 2\% were added to this suspension and pipetted into a plug mould (BioRad Laboratories). Solidified plugs were placed in fresh lysis solution $(6 \mathrm{mM}$ Tris, $\mathrm{pH} 8.0,1 \mathrm{M} \mathrm{NaCl}, 100 \mathrm{mM}$ EDTA, pH 8, Brij 0.5\%, Sodium deoxycholate $0.2 \%$, Sarkosyl $0.5 \%$ ) with $40 \mu \mathrm{l}$ of lysozyme $25 \mathrm{mg} / \mathrm{ml}$ solution, incubated at $37^{\circ} \mathrm{C}$ for $1 \mathrm{~h}$ and washed with $1.5 \mathrm{ml}$ of $1 \times$ washing buffer $(10 \mathrm{~mm}$ Tris- $\mathrm{HC} 1 /$ $0.1 \mathrm{mM}$ EDTA, $\mathrm{pH} 8$ ). The plug was placed in $1 \mathrm{ml}$ of proteinase K buffer (0.5 M EDTA, pH 9, Sarkosyl 1\%) and $40 \mu \mathrm{l}$ of proteinase $\mathrm{K} 25 \mathrm{mg} / \mathrm{ml}$ solution (Roche Molecular Biochemicals) and incubated overnight at $50^{\circ} \mathrm{C}$ without shaking. Plugs were washed three times with $1 \times$ washing buffer with gentle shaking and stored at $4^{\circ} \mathrm{C}$. Small slices of the agarose plugs were incubated overnight at $25^{\circ} \mathrm{C}$ with 25 units of Sma I restriction endonuclease (Roche Molecular Biochemicals) in $400 \mu \mathrm{l}$ of restriction buffer.

The slices were melted and loaded into the wells of Seakem agarose $1 \%$ gels in $0.5 \times \mathrm{TBE}$ buffer. A $\lambda$ ladder PFGE marker (Roche Molecular Biochemicals) was used as a molecular size standard. Electrophoresis was performed with a BioRad Contour Clamped Homogeneous Electric Field Mapper for $27 \mathrm{~h}$ with linearly ramped pulse times beginning with $2 \mathrm{~s}$ and ending with $35 \mathrm{~s}$ at an applied voltage of $6 \mathrm{~V} / \mathrm{cm}$ at $14^{\circ} \mathrm{C}$. The gels were stained with ethidium bromide and photographed with UV transillumination. PFGE profiles were analysed by visual inspection. The DNA restriction patterns of the isolates were compared with each other to determine their relatedness according to the interpretative criteria of Tenover [23]. Isolates differing by more than six restriction fragments were considered to be different and were assigned upper case letters. Isolates with non-identical patterns that differed by six or fewer restriction fragments were considered to be subtypes and were designated by a numerical subcode added to an upper case letter; these strains are considered to be genetically related.

\section{Southern blots}

DNA from PFGE was transferred to nitrocellulose membranes (Hybond N, Amersham) by vacuum blotting. The DNA was hybridised with a digoxigeninlabelled probe of $885 \mathrm{bp}$ obtained by PCR amplification of the van $\mathrm{A}$ gene from the reference strain BM4147 [24]. Hybridisation and colorimetric detection were performed as recommended by the manufacturer (Roche Molecular Biochemicals).

\section{Statistical analysis}

A $\chi^{2}$ test was used to determine differences in the genetic diversity of VRE between the two periods.

\section{Results}

\section{Epidemiological investigation}

In July 1994, VRE was isolated for the first time from the stool of one patient. Four months later, isolates with similar resistance were obtained from other patients. Overall, VRE were isolated from 30 of the 5260 children hospitalised in the four wards (haematology plus oncology, 1920; nephrology, 1788; gastroenterology, 1552) during the 28-month study period, giving a rate of 6 per 1000 admissions. Twenty-six patients were children (18 boys and 8 girls), aged $1-14$ years (mean, 6 years). The other four patients were adults (two males and two females, mean age 19 years) who had been treated in this hospital since childhood. The patients were hospitalised during overlapping periods in three adjacent wards belonging to several subspecialities: haematology $(n=17)$, oncology $(n=6)$, gastroenterology $(n=6)$ and in a nephrology ward $(n=1)$, which is located elsewhere in the building. (Fig. 1).

No specific changes in antibiotic policies accompanied the increase in VRE prevalence during the survey. The majority of patients (29) were colonised by VRE, which was isolated from faeces at levels of $10^{2}-$ 


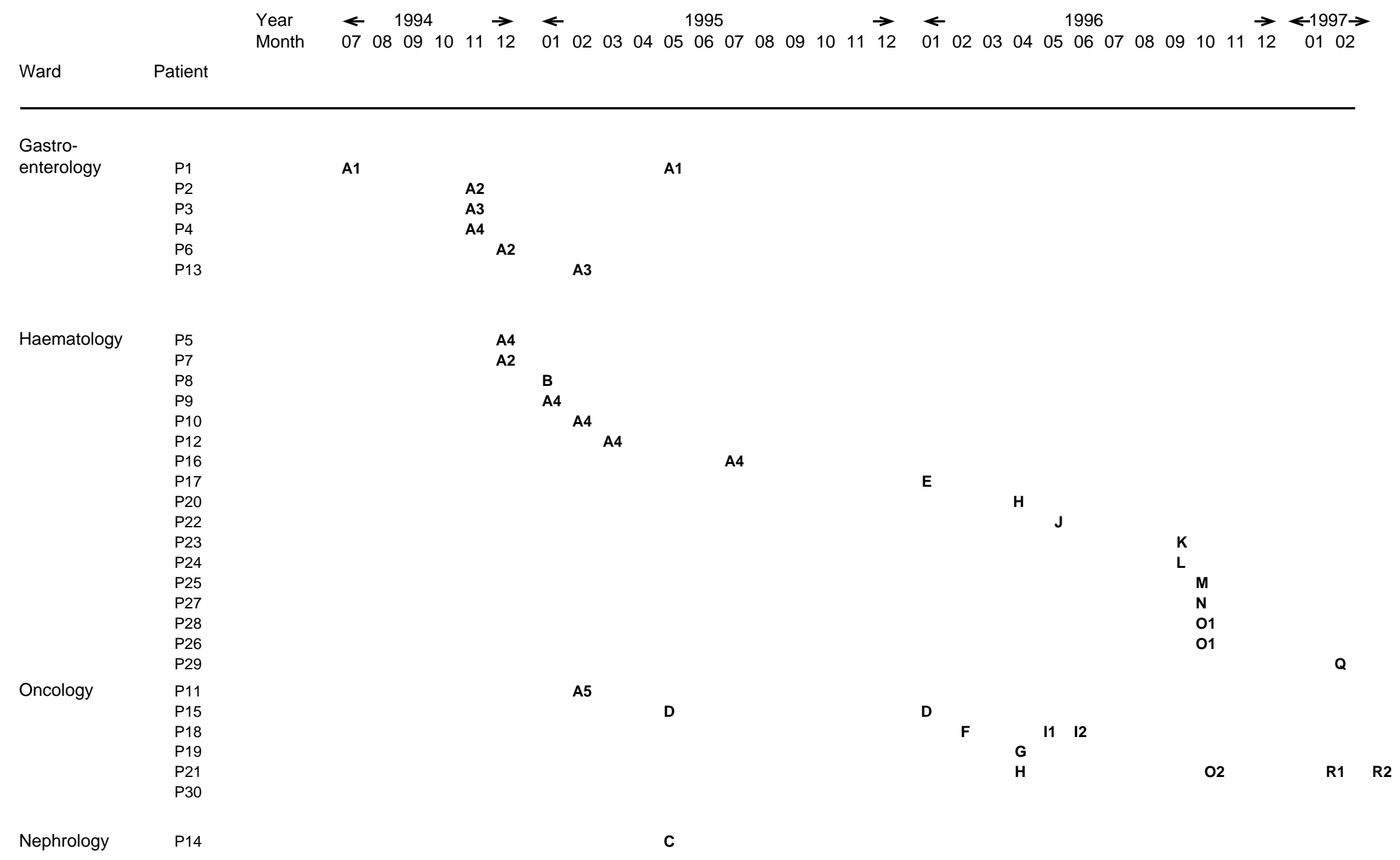

Fig. 1. PFGE patterns and dates of isolation of vancomycin-resistant E. faecium isolates. The patients were hospitalised in four different clinical wards, as indicated. 
$10^{9} \mathrm{cfu} / \mathrm{g}$. Two children had VRE bacteraemia (Table 1, Fig. 1).

\section{Phenotypic analysis}

All the isolates showed high-level resistance to vancomycin (MIC $>256 \mathrm{mg} / \mathrm{L})$ and teicoplanin $(\mathrm{MIC}>16 \mathrm{mg} / \mathrm{L})$ which indicates a VanA phenotype. Eleven isolates were susceptible to amoxicillin (MIC $<1 \mathrm{mg} / \mathrm{L}), 15$ were moderately susceptible $(8-$ $16 \mathrm{mg} / \mathrm{L})$ and 10 were resistant $(>16 \mathrm{mg} / \mathrm{L})$. All the isolates were $\beta$-lactamase-negative. Twenty-nine isolates had high-level resistance to kanamycin and one isolate had high-level resistance to gentamicin. Thirtyone isolates were resistant to macrolide-lincosamidestreptogramin B-type antibiotics. Isolates fell into eight groups on the basis of their antimicrobial susceptibility patterns (Table 1).

\section{PFGE}

The 36 VRE isolates yielded 17 distinct PFGE patterns (A-O, Q and R) and 11 PFGE subtypes (Table 1, Figs. 1 and 2 ). The five epidemiologically unrelated control strains generated four patterns that were distinct from those of the 36 clinical isolates. Two control strains (c and d) obtained from two adult patients from a single hospital were indistinguishable (Fig. 2). Between July 1994 and July 1995, 16 patients were colonised or infected with VRE. Thirteen of them had isolates that displayed a single PFGE pattern (PFGE type A), which contained five subtypes (Fig. 1). The remaining three isolates had unique profiles (B, C and D). From Jan. 1996 to Feb. 1997, 14 patients with newly identified VRE were recognised (Fig. 1). Thirteen of them carried unique PFGE types. Only two patients shared isolates with indistinguishable profiles (P26, P28). In three patients, different PFGE types were isolated at followup, of which two (PFGE types I and R) were closely related. Three patients (P1, P15 and P30) each had an identical isolate (PFGE type A, D and R, respectively) cultured twice from the faeces at intervals of 1,8 and 10 months respectively.

Comparison between the two periods (July 1994-July 1995 and Jan. 1996-Feb 1997) revealed a statistically significant transition from homogeneity to more heterogeneous strain prevalence: in the initial period,

Table 1. Phenotypic and genotypic characteristics of the 36 clinical isolates of vancomycin-resistant E. faecium

\begin{tabular}{|c|c|c|c|c|c|c|c|c|c|}
\hline $\begin{array}{l}\text { Patient } \\
\text { no. }\end{array}$ & $\begin{array}{c}\text { Age } \\
\text { (years) }\end{array}$ & $\begin{array}{l}\text { Clinical } \\
\text { isolate } \\
\text { no. }\end{array}$ & $\begin{array}{l}\text { Date of } \\
\text { isolation }\end{array}$ & Ward & $\begin{array}{l}\text { Isolation } \\
\text { site }\end{array}$ & $\begin{array}{l}\mathrm{cfu} / \mathrm{g} \\
\mathrm{faeces}\end{array}$ & $\begin{array}{l}\text { PFGE } \\
\text { pattern }\end{array}$ & $\begin{array}{l}\text { Size of van A } \\
\text { hybridising } \\
\text { fragment } \\
(\mathrm{kb})\end{array}$ & $\begin{array}{c}\text { Antibiotic } \\
\text { susceptibility } \\
\text { pattern }\end{array}$ \\
\hline $\mathrm{P} 1$ & 6 & RD1 & $30 / 07 / 94$ & Gastro-enterology & Stool & $10^{4}$ & A1 & 40 & A \\
\hline P1 & 6 & RD16 & $30 / 05 / 95$ & Gastro-enterology & Stool & $10^{5}$ & A1 & 40 & A \\
\hline $\mathrm{P} 2$ & 5 & $\mathrm{RD} 2$ & $18 / 11 / 94$ & Gastro-enterology & Stool & $10^{4}$ & $\mathrm{~A} 2$ & 40 & $\mathrm{D}$ \\
\hline P3 & 6 & RD3 & $18 / 11 / 94$ & Gastro-enterology & Stool & $10^{5}$ & A3 & 60 & A \\
\hline P4 & 5 & RD4 & $22 / 11 / 94$ & Gastro-enterology & Stool & $10^{5}$ & A4 & 50 & A \\
\hline P5 & 1 & RD5 & $19 / 12 / 94$ & Haematology & Stool & $10^{4}$ & A4 & 100 & $\mathrm{D}$ \\
\hline P6 & 3 & RD6 & $28 / 12 / 94$ & Gastro-enterology & Stool & $10^{5}$ & $\mathrm{~A} 2$ & 50 & A \\
\hline P7 & 10 & RD7 & $28 / 12 / 94$ & Haematology & Stool & $10^{4}$ & $\mathrm{~A} 2$ & 140 & $\mathrm{C}$ \\
\hline P8 & 1 & RD8 & $02 / 01 / 95$ & Haematology & Stool & $10^{5}$ & $\mathrm{~B}$ & 300 & $\mathrm{D}$ \\
\hline P9 & 1 & RD9 & $12 / 01 / 95$ & Haematology & Stool & $10^{4}$ & A4 & 50 & $\mathrm{D}$ \\
\hline $\mathrm{P} 10$ & 12 & RD10 & $22 / 02 / 95$ & Haematology & Stool & $10^{6}$ & A4 & 50 & $\mathrm{D}$ \\
\hline P11 & 20 & RD11 & $22 / 02 / 95$ & Oncology & Stool & $10^{3}$ & A5 & 30 & $\mathrm{~B}$ \\
\hline $\mathrm{P} 12$ & 10 & RD12 & $08 / 03 / 95$ & Haematology & Stool & $10^{7}$ & A4 & 50 & A \\
\hline P13 & 1 & RD13 & $08 / 03 / 95$ & Gastro-enterology & Blood & - & A3 & 60 & A \\
\hline P14 & 4 & RD14 & $12 / 05 / 95$ & Nephrology & Stool & $10^{8}$ & $\mathrm{C}$ & 50 & $\mathrm{E}$ \\
\hline P15 & 5 & RD15 & $12 / 05 / 95$ & Oncology & Stool & $10^{5}$ & $\mathrm{D}$ & 50 & A \\
\hline P16 & 8 & RD17 & $17 / 07 / 95$ & Haematology & Stool & $10^{7}$ & A4 & 60 & $\mathrm{D}$ \\
\hline P15 & 5 & RD18 & $12 / 01 / 96$ & Oncology & Stool & $10^{5}$ & $\mathrm{D}$ & 50 & $\mathrm{H}$ \\
\hline P17 & 12 & RD19 & $19 / 01 / 96$ & Haematology & Stool & $10^{5}$ & $\mathrm{E}$ & 50 & $\mathrm{~F}$ \\
\hline P18 & 19 & RD20 & $05 / 02 / 96$ & Oncology & Stool & $10^{9}$ & $\mathrm{~F}$ & 60 & $\mathrm{E}$ \\
\hline P18 & 19 & $\mathrm{RD} 24$ & $20 / 05 / 96$ & Oncology & Stool & $10^{6}$ & I1 & 70 & $\mathrm{D}$ \\
\hline P18 & 19 & $\mathrm{RD} 25$ & $20 / 05 / 96$ & Oncology & Blood & - & $\mathrm{I} 2$ & 70 & $\mathrm{D}$ \\
\hline P19 & 19 & $\mathrm{RD} 21$ & $12 / 03 / 96$ & Oncology & Stool & $10^{5}$ & $\mathrm{G}$ & 70 & B \\
\hline $\mathrm{P} 20$ & 8 & $\mathrm{RD} 22$ & $26 / 03 / 96$ & Haematology & Stool & $10^{4}$ & $\mathrm{H}$ & 140 & A \\
\hline $\mathrm{P} 21$ & 3 & RD23 & $26 / 03 / 96$ & Oncology & Stool & $10^{9}$ & $\mathrm{H}$ & 140 & A \\
\hline $\mathrm{P} 22$ & 10 & RD26 & $20 / 05 / 96$ & Haematology & Stool & $10^{4}$ & $\mathrm{~J}$ & 40 & D \\
\hline P23 & 9 & RD27 & $06 / 08 / 96$ & Haematology & Stool & $10^{8}$ & $\mathrm{~K}$ & 30 & $\mathrm{D}$ \\
\hline P24 & 8 & $\mathrm{RD} 28$ & $30 / 08 / 96$ & Haematology & Stool & $10^{3}$ & $\mathrm{~L}$ & 60 & A \\
\hline P25 & 3 & RD29 & $11 / 09 / 96$ & Haematology & Stool & $10^{4}$ & $\mathrm{M}$ & 140 & $\mathrm{E}$ \\
\hline P26 & 1 & RD30 & $11 / 09 / 96$ & Haematology & Stool & $10^{2}$ & $\mathrm{O} 1$ & 90 & G \\
\hline P27 & 5 & RD31 & $30 / 09 / 96$ & Haematology & Stool & $10^{3}$ & $\mathrm{~N}$ & 80 & G \\
\hline $\mathrm{P} 28$ & 1 & RD32 & $30 / 09 / 96$ & Haematology & Stool & $10^{5}$ & $\mathrm{O} 1$ & 90 & $\mathrm{G}$ \\
\hline $\mathrm{P} 21$ & 3 & RD33 & $30 / 09 / 96$ & Oncology & Stool & $10^{8}$ & $\mathrm{O} 2$ & 90 & G \\
\hline P29 & 14 & RD34 & $23 / 01 / 97$ & Haematology & Stool & $10^{6}$ & $\mathrm{Q}$ & 90 & $\mathrm{E}$ \\
\hline P30 & 23 & RD35 & $27 / 01 / 97$ & Oncology & Stool & $10^{5}$ & $\mathrm{R} 1$ & 50 & A \\
\hline P30 & 23 & RD36 & $26 / 02 / 97$ & Oncology & Stool & $10^{5}$ & $\mathrm{R} 2$ & 50 & A \\
\hline
\end{tabular}

Susceptibility patterns are defined as susceptible (S), intermediate (I) or resistant (R) to the antibiotics amoxicillin, macrolide-lincosamidestreptogramin B-type antibiotics, kanamycin and gentamicin, as follows: A, IRRI; B, IRII; C, SSRI; D, RRRI; E, SRRI; F, SRII; G, SSII; H, SRRR; I, low-level resistance to aminoglycosides; R, high-level resistance to aminoglycosides. 


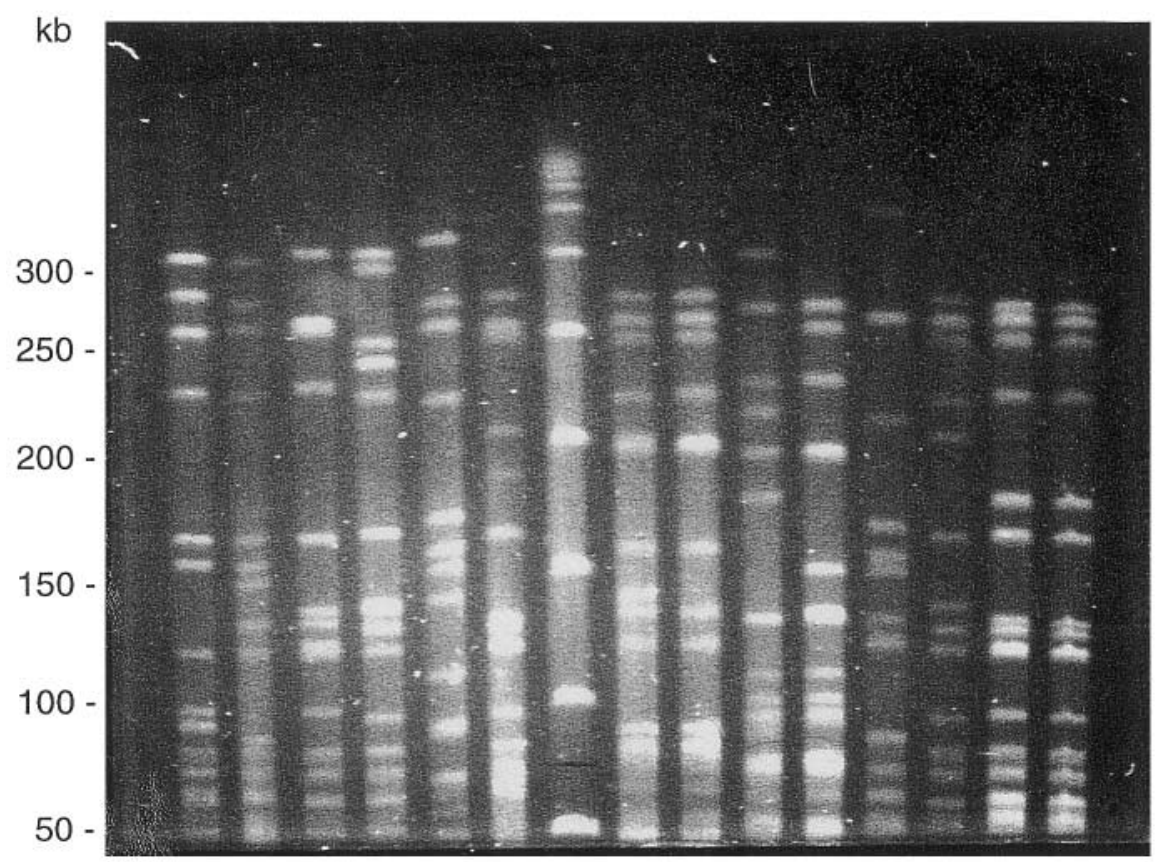

Fig. 2. Representative PFGE patterns of vancomycin-resistant E. faecium isolates. Lanes: 1, isolate RD12 (PFGE type A, subtype A4); 2, isolate RD20 (PFGE type F); 3, isolate RD8 (PFGE type B); 4, isolate RD14 (PFGE type C); 5, isolate RD19 (PFGE type E); 6, isolate RD21 (PFGE type G); M, $\lambda$ phage DNA ladder standard; 7, unrelated isolate c; 8, unrelated isolate d; 9, isolate RD24 (PFGE type I, subtype I1); 10, isolate RD25 (PFGE type I, subtype 12); 11, isolate RD26 (PFGE type J); 12, unrelated isolate b; 13, isolate RD15 (PFGE type D); 14, isolate RD18 (PFGE type D).

$13(81 \%)$ of the 16 patients concerned were colonised or infected by the same strain type, whereas single strain types were isolated from 11 of the 15 children in the second period. $(\mathrm{p}<0.001)$.

\section{Hybridisation of SmaI digests with the VanA probe}

The reference strain yielded a $\operatorname{van} \mathrm{A}$ hybridisation fragment of $34 \mathrm{~kb}$, which corresponds to the size of the plasmid carrying the transposon $T n 1545$ [25]. All the isolates identified as VanA on the basis of their phenotype gave positive hybridisation signals with the vanA probe. The molecular size of vanA probe-positive bands ranged from c. 30 to $300 \mathrm{~kb}$ (Table 1). The most frequent of these was $50 \mathrm{~kb}$ and this was identified in 11 isolates, five of which were PFGE type A. The size of vanA hybridising fragments obtained with PFGE pattern A isolates ranged from c. 30 to $140 \mathrm{~kb}$, some subtypes having the same size and others a different size (Table 1). Some strains with an identical van A hybridising fragment were clearly distinguishable on the basis of their chromosomal macrorestriction pattern (Table 1).

\section{Discussion}

In the last decade enterococci have been recognised as a leading cause of nosocomial infection in children [13-18]. Epidemiological studies are essential to understand the spread of VRE and to draw up preventive measures. Eight patterns of antibiotic susceptibility were found among the 36 VRE clinical isolates in the present study. However, antibiotic resistance patterns do not reliably show sufficient strain-to-strain differences to be used for epidemiological purposes. DNA methods such as ribotyping and PFGE are increasingly used for epidemiological investigations of VRE, PFGE being the most discriminatory $[9,26,27]$. The present study used PFGE combined with Southern hybridisation with a $\operatorname{van} \mathrm{A}-$ specific DNA probe to identify mechanisms contributing to the increased incidence of VRE isolation in this institution.

The data indicate an increase in the overall genomic diversity of the VRE isolates between 1994 and 1997. Two periods could be distinguished. During the first (July 1994-July 1995), a single pattern (PFGE type A) was found in 13 of the 16 culture-positive patients hospitalised in three neighbouring wards. All but one of these patients were colonised, the last having VRE bacteremia. Hybridisation analysis showed that restriction fragments carrying the van $\mathrm{A}$ gene differed in size in some of the isolates over a range compatible with a plasmid or chromosomal location. The prevalence of a common strain suggests that nosocomial transmission occurred between and within wards. Investigations of several outbreaks found that the personnel or the environment played a role in the transmission of enterococci $[1,2,28]$. The present study did not screen 
for surface contamination or staff carriage in these units. Therefore, the nature of the transmission cannot be identified retrospectively. Nevertheless, the bacteria may have been transmitted by transient carriage on the hands of hospital personnel, particularly within a given ward. As it was assumed that VRE at high levels $\left(10^{4}-\right.$ $10^{7} \mathrm{cfu} / \mathrm{g}$ of faeces) in the childrens' stools may facilitate dissemination via several routes, VRE control measures were introduced in July 1995 and included ward isolation of infected and colonised patients, use of disposable gloves, strict hand-washing measures and the restricted use of vancomycin. This policy led to a significant reduction in VRE isolation, as the epidemic strain disappeared and no VRE were isolated during the subsequent 5 months. However, VRE were once again isolated in Jan. 1996. The data showed that the epidemiology of VRE during the period Jan. 1996Feb. 1997 was characterised by a higher level of diversity, as different VRE PFGE types were isolated from 13 of the 14 children involved. The diversity of PFGE patterns was associated with varying vanAcontaining restriction fragment sizes. Reinforcement of hand-washing policy during the second period did not eradicate the endemic situation. It was concluded that the multiplicity of strains in the hospital pointed to multiple reservoirs, the import of vanA-positive VRE from the community via the food chain, horizontal transfer of genetic elements carrying vancomycin resistance genes by recombinant transposition or plasmids, or independent introduction of exogenous VRE by patients colonised on admission [10-12, 18]. The study was unable to determine whether the prevalence of multiple strains was due to transposition events or multiple introduction of vanA-containing strains, as the vanA gene cluster was not typed. Bonten et al. [29] reported that antibiotic use maintained selective pressure on VRE, resulting in the spread of mobile resistance determinants among different enterococcal strains. VRE have been found as part of the normal faecal flora in Europeans, possibly because glycopeptides are often used to treat livestock in Europe, contrary to the situation in the USA. In the present study, changes in the overall epidemiology of VRE during this period seem to have been due to repeated introduction from external sources, as some patients had been referred from other institutions where VRE carriage had been detected.

In conclusion, the endemicity of VRE in this hospital was characterised by a statistically significant transition from low to high strain diversity. Failure of hygienic measures is thought to have been the main cause of cross-contamination in the first period, as the endemicity ceased only when strict control measures were introduced. The genetic diversity in the second period may be the result of recombination or the introduction of new strains from the community or other hospitals. Future control policies shoud take this risk into account by including routine stool culture for VRE detection on admission.
We thank R. Leclercq for providing the reference strain E. faecium BM4147.

\section{References}

1. Handwerger S, Raucher B, Altarc D et al. Nosocomial outbreak due to Enterococcus faecium highly resistant to vancomycin, penicillin, and gentamicin. Clin Infect Dis 1993; 16: $750-755$.

2. Korten V, Murray BE. The nosocomial transmission of enterococci. Curr Opin Infect Dis 1993; 6: 498-505.

3. Murray BE. Diversity among multidrug-resistant enterococci. Emerg Infect Dis 1998; 4: 37-47.

4. Leclercq R, Derlot E, Duval J, Courvalin P. Plasmid-mediated resistance to vancomycin and teicoplanin in Enterococcus faecium. $N$ Engl J Med 1988; 319: 157-161.

5. Uttley AHC, George RC, Naidoo J et al. High-level vancomycin-resistant enterococci causing hospital infections. Epidemiol Infect 1989; 103: 173-181.

6. Chow JW, Kuritza A, Shlaes DM, Green M, Sahm DF, Zervos MJ. Clonal spread of vancomycin-resistant Enterococcus faecium between patients in three hospitals in two states. J Clin Microbiol 1993; 31: 1609-1611.

7. Clark NC, Cooksey RC, Hill BC, Swenson JM, Tenover FC. Characterization of glycopeptide-resistant enterococci from U.S. hospitals. Antimicrob Agents Chemother 1993; 37: 2311-2317.

8. Frieden TR, Munsiff SS, Low DE. Emergence of vancomycinresistant enterococci in New York city. Lancet 1993; 342: 76-79.

9. Montecalvo MA, de Lencastre H, Carraher M et al. Natural history of colonization with vancomycin-resistant Enterococcus faecium. Infect Control Hosp Epidemiol 1995; 16: 680-685.

10. Bates J, Jordens JZ, Griffiths DT. Farm animals as a putative reservoir for vancomycin-resistant enterococcal infection in man. J Antimicrob Chemother 1994; 34: 507-514.

11. Gordts B, van Landuyt H, Ieven M, Vandamme P, Goossens H. Vancomycin-resistant enterococci colonizing the intestinal tracts of hospitalized patients. J Clin Microbiol 1995; 33: $2842-2846$.

12. Jordens JZ, Bates, J, Griffiths DT. Faecal carriage and nosocomial spread of vancomycin-resistant Enterococcus faecium. J Antimicrob Chemother 1994; 35: 515-528.

13. Bingen E, Lambert-Zechovsky NY, Mariani-Kurkdjian $P$, Cezard JP, Navarro J. Bacteremia caused by a vancomycinresistant Enterococcus. Pediatr Infect Dis J 1989; 8: 475-476.

14. Bingen EH, Denamur E, Lambert-Zechovsky NY, Elion J. Evidence for the genetic unrelatedness of nosocomial vancomycin-resistant Enterococcus faecium strains in a pediatric hospital. J Clin Microbiol 1991; 29: 1888-1892.

15. Green M, Wadowsky RM, Barbadora K. Recovery of vancomycin-resistant gram-positive cocci from children. J Clin Microbiol 1990; 28: 484-488.

16. Henning KJ, de Lencastre H, Eagan $\mathrm{J}$ et al. Vancomycinresistant Enterococcus faecium on a pediatric oncology ward: duration of stool shedding and incidence of clinical infection. Pediatr Infect Dis J 1996; 15: 848-854.

17. Rubin LG. Tucci V, Cercenado E, Eliopoulos G, Isenberg HD. Vancomycin-resistant Enterococcus faecium in hospitalized children. Infect Control Hosp Epidemiol 1992; 13: 700-705.

18. Singh-Naz N, Sleemi A, Pikis A, Patel KM, Campos JM. Vancomycin-resistant Enterococcus faecium colonization in children. J Clin Microbiol 1999; 37: 413-416.

19. Bingen E, Lambert-Zechovsky N, Leclercq R, Doit C, MarianiKurkdjian P. Bactericidal activity of vancomycin, daptomycin, ampicillin and aminoglycosides against vancomycin-resistant Enterococcus faecium. J Antimicrob Chemother 1990; 26: 619-626.

20. Bingen E, Lambert-Zechovsky N. Technical aspects of quantitative and differential analysis of microbial intestinal ecosystem. Dev Pharmacol Ther 1984; 7 Suppl 1: 134-137.

21. Lambert-Zechovsky N, Bingen E, Denamur E et al. Molecular analysis provides evidence for the endogenous origin of bacteremia and meningitis due to Enterobacter cloacae in an infant. Clin Infect Dis 1992; 15: 30-32.

22. Schleifer KH, Kilpper-Bâlz R. Transfer of Streptococcus faecalis and Streptococcus faecium to the genus Enterococcus nom. rev. as Enterococcus faecalis comb. nov. and Enter- 
ococcus faecium comb. nov. Int J Syst Bacteriol 1984; 34: $31-34$.

23. Tenover FC, Arbeit RD, Goering RV et al. Interpreting chromosomal DNA restriction patterns produced by pulsedfield gel electrophoresis: criteria for bacterial strain typing. J Clin Microbiol 1995; 33: 2233-2239.

24. Patel R, Uhl JR, Kohner P, Hopkins MK, Cockerill FR. Multiplex PCR detection of $\operatorname{van} \mathrm{A}, \operatorname{van} \mathrm{B}$, van $\mathrm{C}-1$, and $\operatorname{van} \mathrm{C}$ 2/3 genes in Enterococci. $J$ Clin Microbiol 1997; 35: 703-707.

25. Liassine N, Frei R, Jan I, Auckenthaler R. Characterization of glycopeptide-resistant enterococci from a Swiss hospital. J Clin Microbiol 1998; 36: 1853-1858.

26. Barbier N, Saulnier P, Chachaty E, Dumontier S, Andremont A. Random amplified polymorphic DNA typing versus pulsed- field gel electrophoresis for epidemiological typing of vancomycin-resistant enterococci. J Clin Microbiol 1996; 34: 1096-1099.

27. Miranda AG, Singh KV, Murray BE. DNA fingerprinting of Enterococcus faecium by pulsed-field gel electrophoresis may be a useful epidemiologic tool. J Clin Microbiol 1991; 29: 2752-2757.

28. Rhinehart E, Smith NE, Wennersten $\mathrm{C}$ et al. Rapid dissemination of $\beta$-lactamase-producing aminoglycoside-resistant Enterococcus faecalis among patients and staff on an infant-toddler surgical ward. $N$ Engl J Med 1990; 323: 1814-1818.

29. Bonten MJM, Hayden MK, Nathen C et al. Epidemiology of colonisation of patients and environment with vancomycinresistant enterococci. Lancet 1996; 348: 1615-1619. 